\title{
Impact of cutting date on carabids and spiders in a wet meadow
}

Denis Lafage ${ }^{\mathrm{a}, \mathrm{b}, *}$ and Julien Pétillon ${ }^{\mathrm{a}}$

${ }^{\text {a} U n i v e r s i t e ́ ~ d e ~ R e n n e s ~ 1, ~ U R U ~ 420, ~ U M R ~ C N R S ~ U P M C ~ 7204, ~ M u s e ́ u m ~ N a t i o n a l ~ d ' H i s t o i r e ~}$ Naturelle, 263 Avenue du Général Leclerc, CS 74205, 35042 Rennes Cedex, France

bUniversité d'Angers, LUNAM, GECCO, 2 Boulevard Lavoisier, 49045 Angers, France.

*Corresponding author; Email: lafage.denis@ gmail.com ; Tel: +33 228 205167; fax: +33228205075

Running title: Impacts of cutting date 


\begin{abstract}
The impact of different cutting dates on two dominant groups of ground-dwelling arthropods (carabids and spiders) was assessed. Short-term impacts were assessed by comparing them before and after cutting. Arthropods were collected by pitfall traps located in three plots with different cutting dates between June and August and one uncut control plot. Trapping was performed during a 4-month period in the spring and summer 2011. In total, 26,392 spiders and 12,278 carabids, representing 56 and 82 species respectively, were collected. Overall, the effects of cutting were negative and mostly visible in the long term for carabids, with reduced abundances and species richness in cut plots, and in the short-term for spiders; several parameters (proportion of predators and polyphagous species, and body length) decreased after cutting while remaining stable in the control. Long-term cutting effects revealed almost no differences between plots cut at different dates whereas the short-term effects decreased slightly over time, with respect to the overall phenology of both groups. In conclusion, this study underlines the fact that cutting has drastic effects on ground-dwelling arthropods, and even late dates, which are supposedly positive for other animals like breeding birds, are deleterious for highly diverse and species-rich grassland groups.
\end{abstract}

Key words: grassland, carabid beetle, spider, management, mowing period 


\section{Introduction}

Semi-natural grassland is frequently managed to conserve early successional species and assemblages, and to prevent vegetation succession. Cutting is frequently used in habitat conservation to prevent the growth of bushes and trees, and thus maintain semi-natural grassland (Grime, 2001). Its impact on vegetation (e.g. Bakker et al., 2002; Parr and Way, 1988), birds (e.g. Britschgi et al., 2006) and phytophagous arthropods (e.g. Morris and Plant, 1983) has been well studied, but has been less well examined regarding predatory arthropods. Cutting is supposed to have a negative effect on invertebrate diversity in general (Ausden, 2007), and on spiders (Bell et al., 2001; Prieto-Benítez and Méndez, 2011) or leafhoppers (Rothenbücher and Schaefer, 2006) in particular. Arthropods are however a key component of grassland ecosystems, and particularly spiders and carabids that can play a role in pest control (Symondson et al., 2002). Spiders are sensitive to changes in habitat structure (Duffey, 1993), particularly those impacting the spatial arrangement of vegetation and litter structures (Uetz, 1991). Baines et al. (1998) reported that, for field margins, the timing of some regimes is more favourable than others: spring and autumn cutting regimes have much less severe effects on the spider community than those with summer cuts, particularly those combined with a spring cut. Purvis and Curry (1981) also suggested that availability of prey, such as Collembola, may be drastically reduced following cutting, thus affecting specialised spiders. Carabids are usually considered to be dependent on several abiotic and biotic factors, including i) temperature or humidity, ii) food conditions, iii) presence and distribution 
of competitors, and iv) life history and season, including migration between hibernation and reproduction habitats (Lövei and Sunderland, 1996).

In this study, the impact of different dates of cutting on two dominant groups of ground-dwelling macro-arthropods, ground beetles and spiders, was assessed. Long- and short-term impacts of cutting date were distinguished by comparing assemblages among treatments before/after cutting respectively. More specifically, changes in species richness, total abundance, and traits (niche size, and trophic guild) were investigated by comparing plots differing in cutting dates with a control uncut plot. We hypothesised that cutting per se would have a negative long-term impact on activitydensity and species-richness of both groups and would favour generalist species. The reduction of vegetation complexity and litter-depth could have a negative effect on web-building spiders. Late cutting date induces vegetation modifications by favouring annual plant species. So, we expected cutting date to have a long-term impact on carabids' diet. Short-term impact of cutting per se was expected to be strong especially on activity-density, species-richness and species length. We also expected strong modifications in habitat preferences. Short-term cutting-date impact was expected to be linked to group phenology, early and late cutting having more negative impacts. 


\section{Methods}

The study site was located near the city of Angers, western France (Long: 0³2'37.7" W Lat: $\left.47^{\circ} 30^{\prime} 05.6^{\prime \prime} \mathrm{N}\right)$. It was a 600 ha island encircled by two rivers and flooded for about three mo each year. The land was mainly covered by hay meadows and a few poplar groves. Grassland were generally cut in summer and grazed by cattle in autumn. Fertilizers have been forbidden for $20 \mathrm{y}$.

\subsection{Sampling method}

Ground beetles and spiders were sampled in four plots, all being completely covered by meadows. Three plots were under environmental contracts that delayed cutting to a fixed date (E (early): 20/06, M (medium): 10/07, L (late): 20/07) whereas the last one, plot C (control), was not managed except by grazing in autumn. Due to an extremely dry spring followed by a wet summer, farmers had to change the cutting dates in 2011. Early cutting took place on 24th June (instead of the 20th), mid cutting on 28th July (instead of the 10th) and late cutting on 17th August (instead of 20th July). Plots E, M and L belonged to the Oenanthion fistulosae (de Foucault, 1984) phytosociological association and plot $\mathrm{C}$ belonged to the Bromion racemosi (Tüxen in Tüxen and Preising, 1951) phytosociological association (see 2.3 for description of phytosociological relevés). Management of the four plots has remained unchanged for at least 15 years. Plots E, M and L were separated from 
each other by small channels (1m width). Plot E covered 2.9 ha; plot M, 1.4 ha; plot L, 1.9 ha and the control plot covered 0.4 ha. In this study, despite the existence of true replicates within each plot, plots were confounded with the management treatment which can be considered as a case of pseudoreplication in the sense of Hurlbert (1984). Consequently, we increased the spatial sampling effort (Lövei and Magura, 2011), by placing numerous replicated sampling units per plot.

Sampling was carried out from the 5th May to 31th August 2011, before cattle introduction. Ten traps (100 mm diam.) per plot were set in a square grid. Traps were located at least $25 \mathrm{~m}$ from the plot margins and $20 \mathrm{~m}$ away from each other to avoid edge effects and interactions between traps (Topping and Sunderland, 1992). The pitfall traps were filled with preservative solution (50\% monoethylene glycol, 50\% water) and emptied every two weeks. In addition, a few days before each cut, all pitfall traps were emptied to prevent destruction and to allow between plot comparisons to be made.

\subsection{Species identification and functional traits.}

Carabids and spiders were identified to species and classified into two classes of habitat preference using Hänggi et al. (1995) and Harvey et al. (2002) for spiders, and Luff (1998) and Bouget (2004) for carabids. Species associated with grassland were classified as specialists and ubiquitous species or stenotopic species not associated specifically with grassland as generalists. Spiders were 
classified into three guilds (ground runners, ambush hunters, or web-builders according to their hunting strategy. According to their diet, carabids were classified into three guilds: predators, phytophagous or polyphagous. Length of each species was defined according to Roberts (1995) and Harvey et al. (2002) for spiders and to Luff (1998) and Jeannel (1941-1942) for carabids.

\subsection{Soil and vegetation characteristics}

Soil moisture (M) and temperature (T) were measured on 20th May and 6th June, 2011 using a W.E.T. sensor (five cm deep) connected to a moisture meter HH2 (both by Delta-T Devices Ltd., Cambridge, UK). Two measurements per sampling point (pitfall trap) were realized and the data were averaged.

Phytosociological observations were carried out on 6th June (i.e. before cutting) using the BraunBlanquet (1928) approach in a $1 \mathrm{~m}^{2}$ quadrat around each sampling point. Maximum and average vegetation height and litter depth were measured to the nearest $\mathrm{cm}$. The Normalized Difference Vegetation Index (NDVI), a satellite-derived vegetation index (Tucker, 1979) has been shown to be a useful estimate of productivity and a quantifier of vegetation-related spatial heterogeneity (Levin et al., 2007). NDVI calculation was carried out using Grass GIS software (Geographic Resources Analysis Support System) applied to a SPOT image (2.5 m resolution, 3 bands) acquired in May 2011 (CCNES (2011), Distribution Spot Image S.A.). NDVI is defined as: 
$\mathrm{NDVI}=\left(\mathrm{R}_{\mathrm{NIR}}-\mathrm{R}_{\mathrm{VIS}}\right) /\left(\mathrm{R}_{\mathrm{NIR}}+\mathrm{R}_{\mathrm{VIS}}\right)$

where $R_{N I R}$ and $R_{V I S}$ refer to the reflectance values derived from spectral radiances measured by the near-infrared channel and the visible channel, respectively.

\subsection{Statistical analysis}

Soil and vegetation characteristics were compared between plots using Generalised Linear Models (GLMs) with binomial distribution. When GLM revealed a significant effect of "plot" factor, Tukey's post-hoc tests with Bonferroni correction for multiple comparisons were performed between mean parameters.

Catches in pitfall traps were divided by trapping duration in order to calculate an 'activity density' (the number of individuals per day: Sunderland et al., 1995). To evaluate the impact of cutting date, we studied activity-density $(\log (n+1)$ with $n$ as the number of individuals per day), species richness, community weighted mean traits (CWM) (Lavorel et al., 2008) and functional diversity (FD). Functional diversity was computed using Rao's quadratic entropy (Botta-Dukát, 2005). CWM and FD were computed using FD package (Laliberté and Legendre, 2010).

To verify independence in the time series before cutting we performed Box-Pierce tests on each plot. The tests demonstrated independence in the time series for all plots, for both carabids (plot E: 
$\chi^{2}=0.60, \mathrm{P}=0.438$; plot $\mathrm{M}: \chi^{2}=0.20, \mathrm{P}=0.653$; plot $\mathrm{L}: \chi^{2}=0.99, \mathrm{P}=0.318$; plot $\mathrm{C}: \chi^{2}=0.96, \mathrm{P}=0.326$ )

and spiders (plot $\mathrm{E}: \chi^{2}=0.95, \mathrm{P}=0.331$; plot $\mathrm{M}: \chi^{2}=0.01, \mathrm{P}=0.968$; plot $\mathrm{L}: \chi^{2}=0.98, \mathrm{P}=0.322$; plot $\mathrm{C}$ : $\left.\chi^{2}=7 \mathrm{e}-04, \mathrm{P}=0.980\right)$; so data were not pooled.

In order to test for differences in species richness and activity-density (total and per ecological trait) between the four plots (i.e. the long-term impact of cutting), GLMs with quasi-Poisson distribution were performed using data from the individual traps (Vincent and Haworth, 1983; O'Hara and Kotze, 2010) before the first cut took place. When GLM revealed a significant effect of "plot" factor, Tukey's post-hoc tests with Bonferroni correction for multiple comparisons were performed between mean parameters.

As the same trap was operative before and after cutting, abundances were pair-matched over time and consequently compared using repeated analysis of variance (R-ANOVA); see Pétillon et al. (2010) for such statistical treatments and analyses of catches by traps over time. Three trapping series, before and after cutting, were used for early and medium cuts and two were used for the late one (due to cattle introduction). In the case of a significant cutting effect, the interaction between within-subject factor and the fixed factor 'management' was expected to be significant.

Tests were performed for both spiders and carabids using total activity-density, species richness and traits as dependent variables, management (cut or uncut: each cut plot was compared with the uncut control) as a fixed factor, and period (pre- vs. post-cutting) as a within subject effect. If the 
interaction between fixed factors was not significant (in model 1), a second GLM (model 2) was used to test significant effects of separated fixed factors, without their interaction. If the interaction was significant, t-tests were used to detect significant differences between sampling periods (i.e., differences between plots which were independent from periods were not of interest here). In the case of short-term cutting effects, a significant interaction between management and period was indeed expected (i.e. the within subject factor being expressed differentially for the two plots due to cutting effects in one of them). For each analysis, the level of statistical significance used was $\alpha=0.05$. Results were expressed as mean \pm s.e.

Prior to analysis, normality and homogeneity of variances were checked by Shapiro-Wilk tests and Levene tests repsectively, and data were $\log (\mathrm{x}+1)$ transformed; sphericity assumption was tested by Mauchly's Test before applying R-ANOVAs.

All statistical analyses were performed using the R software ( $\mathrm{R}$ Development Core team 2011). The Levene tests were performed using the Lawstat package (Noguchi et al., 2012). Post-hoc tests were performed using the Asbio package (Aho, 2012).

\section{Results}

The control plot differed clearly from the cut plots, as it presented greater litter-depth and NDVI, and had lower number of plant species and soil temperature (Table 1). Cutting generally removed 
all litter and induced lower plant species richness and biomass. No constant differences were found among cut plots: plot $\mathrm{M}$ was significantly different from plot $\mathrm{E}$ for maximum height of vegetation and moisture. All plots differed significantly regarding soil temperature.

A total of 26,392 spiders, of 56 species (see taxonomic list in Appendix 1) representing nine families, were trapped. Lycosidae were highly dominant (79.6\% of individuals) followed by Linyphiidae (8.2\%) and Thomisidae (7.4\%). One species accounted for almost $60 \%$ of adult individuals: Pardosa prativaga.

A total of 12,278 adult carabids, belonging to 82 species (see taxonomic list in Appendix 2) and 12 tribes, were collected. Two species (Harpalus rufipes and Poecilus cupreus) accounted for more than $57 \%$ of individuals.

\subsection{Long-term impact of cutting date}

There was no significant difference among plots for both activity-density and species richness of spiders (Table 2). In contrast, activity-density and species richness of carabids were significantly higher in the control (C) than in the cut plots (Table 2) with no difference between the cut plots. A significant long-term impact of cutting date was found on the hunting guild of spiders with more ambush hunters in plot $\mathrm{M}$ than in plots $\mathrm{L}$ and $\mathrm{C}$, and less ground runners in plot $\mathrm{M}$ than in plot $\mathrm{L}$ 
(Appendix 4). Those differences in CWM trait values were not retrieved in functional diversity of spiders' hunting guilds.

Significant differences were found for carabid diet (Table 2). Indeed the control plot had fewer phytophagous than plot L and more polyphagous species than plot M (Appendix 5). Carabids were also larger in the control plot (Appendix 5). These differences were retrieved for carabid total FD and diet FD, the control plot presenting smaller values than plots $\mathrm{M}$ and $\mathrm{L}$.

\subsection{Short-term impact of cutting date}

Overall, most significant effects were found for the period factor, with significant effects decreasing over time. Plot factor was mostly significant for carabids. The interaction between period and plot factors was significant only nine times out of 36 for carabids and eight times out of 36 for spiders, indicating few short-term effects of cutting period (Appendix 3).

\subsubsection{Spiders}

For the early cutting date, a significant interaction between "management" and "period" effects was found for total activity/density. Total activity-density decreased after cutting $(\mathrm{t}=-5.54, \mathrm{df}=9$, 
$\mathrm{P}<0.001)$ in the early cut plot, whereas activity-density did not change in the control $(\mathrm{t}=-1.70, \mathrm{df}=9$, $\mathrm{P}=0.123$ ) (Figure 1).

Significant interactions were found for several CWM trait values: web-builders and ambush-hunters CWM, specialist and generalist CWM and length CWM (Appendix 3). The interaction found for web-builders was due to an increase in this guild in the control plot $(\mathrm{t}=9.04, \mathrm{df}=13.64, \mathrm{P}<0.001)$ (Appendix 6). The interaction found for ambush-hunters was due to an increase in this guild in the cut plot $(\mathrm{t}=3.35, \mathrm{df}=1.14, \mathrm{P}=0.006)$ whereas it remained stable in the cut plot $(\mathrm{t}=0.02, \mathrm{df}=11.35$, $\mathrm{P}=0.984)$. The interactions found for specialists and generalists were due to an increase in generalists (plot $\mathrm{E}: \mathrm{t}=-2.66, \mathrm{df}=9, \mathrm{P}=0.026$; plot $\mathrm{C}: \mathrm{t}=8.98, \mathrm{df}=12.19 \mathrm{P}<0.001$ ) and a decrease in specialists in the two plots (plot $E: t=-2.66, d f=9, P=0.026$, plot $C: t=-8.97, d f=12.18, P<0.001$ ), changes being greater in the control plot. A significant decrease in spider length was also detected in the control plot $(\mathrm{t}=-10.85, \mathrm{df}=9, \mathrm{P}<0.001)$ while it remained stable in the cut plot $(\mathrm{t}=-1.28, \mathrm{df}=9$, $\mathrm{P}=0.232$ ). No significant interaction was found for spiders functional diversity.

For the medium cutting date, a significant interaction was found between "management" and "period" effects for total activity-density and species richness of spiders (Appendix 3). Activitydensity $(\mathrm{t}=-1.91, \mathrm{df}=9, \mathrm{P}=0.089)$ and species richness $(\mathrm{t}=-0.17, \mathrm{df}=9, \mathrm{P}=0.872)$ remained stable in the control plot whereas cutting led to a significant decrease in these variables (respectively : $\mathrm{t}=-$ 6.72, $\mathrm{df}=9, \mathrm{P}<0.001$ and $\mathrm{t}=-4.92, \mathrm{df}=9, \mathrm{P}<0.001$ ) in the cut site (Figures 1 and 2 ). The impact on total activity-density was slightly lower than that observed for early cutting; the differences of 
estimated average being -0.747 and -0.102 respectively. No significant interaction was found for spider CWM traits values or functional diversity.

For the late cutting date, no interaction was found, whatever the variable tested for spiders (Appendix 3).

\subsubsection{Carabids}

For the early cutting-date, no significant interaction was found for activity-density or species richness (Appendix 3). We found significant interactions for predators and length CWM values. Predators decreased in the control plot $(\mathrm{t}=-3.95, \mathrm{df}=15.24, \mathrm{P}=0.001)$ while they remained stable in the cut plot $(\mathrm{t}=1.40, \mathrm{df}=14.97, \mathrm{P}=0.180)$ (Appendix 7). Length increased in the cut plot $(\mathrm{t}=4.95$, $, \mathrm{df}=18, \mathrm{P}<0.001)$ while it remained stable in the control plot $(\mathrm{t}=-0.36,17.64, \mathrm{P}=0.720)$ (Appendix 8).

For the medium cutting-date, no significant interaction was found for activity-density and speciesrichness. A significant one was found for predator CWM, but variations before/after cutting were not significant (Control plot: $\mathrm{t}=1.82, \mathrm{df}=11.43, \mathrm{P}=0.10$; cut plot $(\mathrm{M}): \mathrm{t}=-0.47, \mathrm{df}=17.63, \mathrm{P}=0.64)$.

For the late cutting-date, no significant interaction was found for activity-density and speciesrichness, but significant interactions were found for several CWM trait values. The length of 
carabids decreased significantly in the cut plot $(\mathrm{t}=-2.72, \mathrm{df}=12.37, \mathrm{P}=0.018)$ but did not change in the control plot $(\mathrm{t}=1.10, \mathrm{df}=8, \mathrm{P}=0.305)$. Polyphagous decreased significantly in the cut plot $(\mathrm{t}=-$ 2.73, $\mathrm{df}=10.36, \mathrm{P}=0.021)$ while remaining stable in the control plot $(\mathrm{t}=0.46, \mathrm{df}=8.16, \mathrm{P}=0.657)$ (Appendix 9). Predators increased significantly in the cut plot $(\mathrm{t}=2.63$, $\mathrm{df}=10, \mathrm{P}=0.025)$ while remaining stable in the control plot $(\mathrm{t}=-0.25, \mathrm{df}=8.41, \mathrm{P}=0.809)$ (Appendix 7). Significant interactions were found for total, length and diet functional diversity but all the variations were not significant: Total FD: control plot: $\mathrm{t}=1.19, \mathrm{df}=15.88, \mathrm{P}=0.250$; cut plot $(\mathrm{L}): \mathrm{t}=-0.53, \mathrm{df}=8.42$, $\mathrm{P}=0.608$; length $\mathrm{FD}$ : control plot: $\mathrm{t}=1.37, \mathrm{df}=7.96, \mathrm{P}=0.189$; cut plot $(\mathrm{L})$ : $\mathrm{t}=0.40$, $\mathrm{df}=15.91$, $\mathrm{P}=0.703$; diet $\mathrm{FD}$ : Control plot: $\mathrm{t}=2.01, \mathrm{df}=8.36, \mathrm{P}=0.063$; cut plot $(\mathrm{L}): \mathrm{t}=-0.44, \mathrm{df}=15.57$, $\mathrm{P}=0.673$.

\section{Discussion}

In our study, the unmanaged plot supported larger and more diversified carabid beetle communities. These results are consistent with those obtained during the second (short-term) analysis, because the difference between cut and control plots was revealed by the numerous significant effects of the management factor for carabids. This is consistent with the general assumption that management practices, and increased disturbance, decrease the numbers of species and individual carabids (Rushton et al., 1989; Blake et al., 1996; Kotze and Samways, 1999). Another explanation is given 
by the higher productivity and complexity of the control plot, as revealed by its NDVI value. This vegetation index is known to be a good predictor of carabid beetle species richness and activitydensity (Australian forests: Lassau and Hochuli, 2008, French meadows: Lafage et al., 2013). In contrast, cutting is reported to have few effects, or if any they are positive, on species richness of both spiders and carabids in salt marshes (Pétillon et al., 2005, 2007).

The plot with the medium cutting date presented a higher proportion of ambush hunters which mechanically led to smaller proportion of ground runners. Ambush hunters were mainly represented by Ozyptila simplex (87.7\% of ambush hunter individuals).

Cutting-date had no impact on carabid traits, but cutting per-se affected both diet and length. The fact that carabids of the control plot presented greater lengths, has to be linked to the two dominant polyphagous species present in this plot: Harpalus affinis and $H$. griseus. This resulted in a smaller functional diversity of carabid diet in the control plot.

Short-term effects of cutting decreased over time, which is consistent with the phenology of the groups studied. Most species collected were spring breeders, with decreasing activity from June, and a second peak in autumn (for spiders, see Aitchison, 1984 and Schaefer, 1976; for carabids, see Lövei and Sunderland, 1996 and Kotze et al., 2011).

A decrease in the activity-density of spiders was found in the early-cut plot, together with a stronger increase in the proportion of web-builders in the control plot. The numerous impacts on 
spiders' functional traits were linked to the occurrence of Pelecopsis mengei which accounted for more than $80 \%$ of Linyphiidae, and was trapped nearly exclusively in the control plot (> $95 \%$ of all individuals).

Cutting at the end of July had most impact on spiders and affected total activity-density and species richness but not functional traits. Spiders were not impacted at all by late cutting.

Short term effect of cutting was less important on carabids. For the early cutting date, a significant interaction was found for predatory carabids, but it was due to the decrease of this group in the control plot. This weak influence of regime variations is in accordance with Haysom et al. (2004) who found that carabid responses to the three headland cutting regimes took the form of changes in the relative abundance-activity of individual species rather than presence or absence from particular regimes. The impact of medium date was negligible and that of late cutting weak, with a decrease in large and polyphagous carabids in the cut plot, but this may have important implications for conservation. Indeed, very large carabid species, and species associated with both very wet and very dry habitats are considered as conservation priorities (Kotze et al., 2011; Brooks et al., 2012). These results are consistent with the findings of Cole et al. (2005) for carabids, but not for spiders. Cole et al. (2005) found that extensively managed land had a higher relative abundance of large ground beetle (genus Carabus) and wolf spider (family Lycosidae) species. Large species tend to have long life-cycles and consequently require a degree of resource stability over time (Blake et al., 1994). Carabids with low dispersal abilities are also known to react more to disturbances than other, 
smaller, more mobile species (e.g., in agricultural fields and grassland: Hendrickx et al., 2009 and Wamser et al., 2012 respectively). A significant interaction was found for predatory carabids but it was due to an increase of this group in the cut plot. The open vegetation resulting from cutting might facilitate prey capture for predators resulting in an increase of the group ("hunting efficiency hypothesis").

Overall, cutting had different short-term effects on both groups, with more short-term impacts on spiders. Spiders are well known for their ability to react quickly to some changes in vegetation structure (e.g. Duffey, 1993). Cole et al. (2005) found that, despite an observed relationship between spider and ground beetle assemblages, the highest number of carabid species occurred in intensively managed grassland and arable sites, while the highest number of spider species occurred in seminatural grassland and heather sites. Spiders high dispersal tendency over both short and long distances, (Bell et al., 2005), could explain the differences in their response times (see Varet et al., 2013, who also found a similar difference in response time between carabids and spiders).

Our results suggest a higher sensitivity of spiders to short-term management effects. In accordance with Bell et al. (2001), we suggest that it would be beneficial to avoid summer cuts where possible and to keep the intensity of cutting as low as possible. As it seems that no ideal cutting-date exists if a multi-taxa conservation approach is performed, we suggest that heterogeneous cutting-dates at 
local to landscape scales should be promoted to diversify mowing regimes, as indicated by Cizek et al. (2012).

\section{Acknowledgements}

We would like to thank Jean Secondi (Université d'Angers, UNAM, GECCO) for managing the project, Arnaud Horellou for his help in identifying problematic carabids, Jean Paillat for field and laboratory assistance, and Aldyth Nys for editing the English. This study was funded by 'Plan Loire Grandeur Nature' (FEDER), 'Région Pays de la Loire' and 'Agence de l'Eau Loire-Bretagne'. 


\section{References}

Aho, K., 2012. Asbio: A collection of statistical tools for biologists. R package version 0.4-11. Available at: http://CRAN.R-project.org/package=asbio

Aitchison, C.W., 1984. The phenology of winter-active spiders. J. Arachnol. 12, 249-271.

Ausden, M., 2007. Habitat Management for Conservation: A Handbook of Techniques. Techniques in Ecology and Conservation Series First. Oxford University Press, Oxford.

Baines, M., Hambler, C., Johnson, P.J., Macdonald, D. W., Smith, H., 1998. The effects of arable field margin management on the abundance and species richness of Araneae (spiders). Ecography. 21:74-86.

Bakker, J.P., Elzinga, J.A., Vries, Y., 2002. Effects of long-term cutting in a grassland system: perspectives for restoration of plant communities on nutrient-poor soils. Appl. Veg. Sci. 107120.

Bell, J.R., Bohan, D.A., Shaw, E.M., Weyman, G.S., 2005. Ballooning dispersal using silk: world fauna, phylogenies, genetics and models. B. Entomol. Res. 95, 69-114.

Bell, J.R., Wheater, C.P., Cullen, W.R., 2001. The implications of grassland and heathland management for the conservation of spider communities: a review. The zoological Society of London. 255, 377-387.

Blake, S., Foster, G.N., Eyre, M.D., Luff, M.L., 1994. Effects of habitat type and grassland management practices on the body size distribution of carabid beetles. Pedobiologia. 38, 502512.

Blake, S., Foster, G.N., Fisher, G.E.J., Ligertwood, G.L., 1996. Effects of management practices on the carabid faunas of newly established wildflower meadows in southern Scotland. Ann. Zool. Fenn. 33,139-147.

Botta-Dukát, Z. 2005. Rao's quadratic entropy as a measure of functional diversity based on multiple traits. Journal of Vegetation Science, 16, 533-540.

Bouget, C., 2004. Chablis et diversité des coléoptères en forêt feuillus de plaine: Impact à court terme de la trouée, de sa surface et de son contexte paysager. $\mathrm{PhD}$ thesis, Muséum d'Histoire Naturelle de Paris, France. 
Braun-Blanquet, J., 1928. Pflanzensoziologie. Grundzüge der Vegetationskunde. Springer,Wien, Austria.

Britschgi, A., Spaar, R., Arlettaz, R., 2006. Impact of grassland farming intensification on the breeding ecology of an indicator insectivorous passerine, the whinchat Saxicola rubetra: lessons for overall alpine meadowland management. Biol. Conserv. 130, 193-205.

Brooks, D.R., Bater, J.E., Clark, S.J., Monteith, D.T., Andrews, C., Corbett, S.J., Beaumont, D.A., Chapman, J.W., 2012. Large carabid beetle declines in a United Kingdom monitoring network increases evidence for a widespread loss in insect biodiversity. J. Appl. Ecol. 49,1009-1019.

Cizek, O., Zamecnik, J., Tropek, R., Kocarek, P., Konvicka, M., 2012. Diversification of mowing regime increases arthropods diversity in species-poor cultural hay meadows. J. Insect Conserv. $16,215-226$.

Duffey, E., 1993. A review of factors influencing distribution of spiders with reference to Britain. Mem. Queens. Mus. 33, 497-502.

Grime, J.P., 2001. Plant Strategies, Vegetation Processes, and Ecosystem Properties. 2nd edition. Wiley, Chichester, UK.

Hänggi, A., Stöckli, E., Nentwig, W., 1995. Habitats of Central European Spiders. Characterisation of the habitats of the most abundant spider species of Central Europe and associated species. Misc. faun. Helv. 4.

Harvey, P.R., Nellist, D.R., Telfer, M.G., 2002. Provisional Atlas of British Spiders (Arachnida, Araneae). Biological Records Center, Huntington, Cambridgeshire, UK.

Haysom, K.A., McCracken, D.I., Foster, G.N., Sotherton, N.W., 2004. Developing grassland conservation headlands: response of carabid assemblage to different cutting regimes in a silage field edge. Agric. Ecosyst. Env. 102, 263-277.

Hendrickx, F., Maelfait, J-P., Desender, K., Aviron, S., Bailey, D., Diekotter, T., Lens, L., Liira, J., Schweiger, O., Speelmans, M., Vandomme, V., Bugter, R., 2009. Pervasive effects of dispersal limitation on within- and among-community species richness in agricultural landscapes. Global Ecol. Biogeogr. 18, 607-616.

Hurlbert, S.H., 1984. Pseudoreplication and the design of ecological field Experiments. Ecological Monographs. 54, 187-211. 
Jeannel, R. 1941-1942. Faune de France 39. Coléoptères Carabiques première et deuxième partie. Paul Lechevalier et fils, Ed. Paris, France.

Kotze, D.J., Brandmayr, P., Casale, A., Dauffy-Richard, E., Dekoninck, W., Koivula, M.J., Lövei, G.L., Mossakowski, D., Noordijk, J., Paarmann, W., Pizzolotto, R., Saska, P., Schwerk, A., Serrano, J., Szyszko, J., Taboada, A., Turin, H., Venn, S., Vermeulen, R., Zetto, T., 2011. Forty years of carabid beetle research in Europe - from taxonomy, biology, ecology and population studies to bioindication, habitat assessment and conservation. Zookeys. 148, 55-148.

Kotze, D.J., Samways, M.J., 1999. Support for the multi-taxa approach in biodiversity assessment, as shown by epigaeic invertebrates in an Afromontane forest archipelago. J. Insect Conserv. $143,125-143$.

Lafage D., Secondi J., Georges A., Bouzillé J.-B. and Pétillon J. in press. Satellite-derived vegetation indices as surrogate of species richness and abundance of ground beetles in temperate floodplains. Insect Conserv. Diver. DOI : 10.1111/icad.12056.

Laliberté, E., and Legendre, P. 2010. A distance-based framework for measuring functional diversity from multiple traits. Ecology, 91, 299-305.

Lassau, S.A., Hochuli, D.F., 2008. Testing predictions of beetle community patterns derived empirically using remote sensing. Divers Distrib. 14, 138-147.

Lavorel, S., Grigulis, K., McIntyre, S., Williams, N. S. G., Garden, D., Dorrough, J., Berman, S., Quétier, F., Thébault, A., Bonis, A., 2008. Assessing functional diversity in the field methodology matters! Funct. Ecol. 22, 134-147.

Levin, N., Shmida, A., Levanoni, O., Tamari, H., Kark, S., 2007. Predicting mountain plant richness and rarity from space using satellite-derived vegetation indices. Divers Distrib. 13, 692-703.

Luff, M.L., 1998. Provisional Atlas of the Ground Beetles (Coleoptera, Carabidae) of Britain. Biological Records Centre, Huntington, UK.

Lövei, G.L., Magura, T., 2011. Can carabidologists spot a pitfall? The non-equivalence of two components of sampling effort in pitfall-trapped ground beetles (Carabidae). Community Ecol. $12,18-22$.

Lövei, G.L., Sunderland, K.D., 1996. Ecology and behaviour of ground beetles (Coleoptera: Carabidae). Annu. Rev. Entomol. 41, 231-56. 
Morris, M.G., Plant, R., 1983. Responses of grassland invertebrates to management by cutting. V. Changes in hemiptera following cessation of management. J. Appl. Ecol. 20, 157-177.

Noguchi, K., Hui, W.L.W., Gel, Y.R., Gastwirth, J.L. ,Miao, W., 2012. lawstat: An R package for biostatistics, public policy, and law. R package version 2.4. Available at: http://CRAN.Rproject.org/package=lawstat

O’Hara, R.B., Kotze, D.J., 2010. Do not log-transform count data. Meth. Ecol. Evol. 1, 118-122.

Parr, T.W., Way, J.M., 1988. Management of roadside vegetation: the long-term effects of cutting. J. Appl. Ecol. 25, 1073-1087.

Pétillon, J., Georges, A., Canard, A., Ysnel, F., 2007. Impact of cutting and sheep grazing on ground-active spiders and carabids in intertidal salt marshes (Western France). Anim. Biodivers. Conserv. 30, 201-209.

Pétillon, J., Lasne, E., Lambeets, K., Canard, A., Vernon, P., 2010. How do alterations in habitat structure by an invasive grass affect salt-marsh resident spiders? Ann. Zool. Fenn. 47, 79-89.

Pétillon, J., Ysnel, F., Canard, A., Lefeuvre, J., 2005. Impact of an invasive plant (Elymus athericus) on the conservation value of tidal salt marshes in western France and implications for management: Responses of spider populations. Biol. Conserv. 126, 103-117.

Prieto-Benítez, S., Méndez, M., 2011. Effects of land management on the abundance and richness of spiders (Araneae): A meta-analysis. Biol. Conserv. 144, 683-691.

Purvis, G., Curry, J.P., 1981. The influence of sward management on foliage arthropod communities in a ley grassland. J. Appl. Ecol. 18, 711-725.

R Development Core team, 2011. R: A Language and Environment for Statistical Computing.

Roberts, M.J., 1995. The Spiders of Britain and Northern Europe. Harper Collins Publisher, London, UK.

Rothenbücher, J., Schaefer, M., 2006.Submersion tolerance in floodplain arthropod communities. Basic. Appl. Ecol. 7, 398-408.

Rushton, S.P., Luff, M.L., Eyre, M.D., 1989. Effects of pasture improvement and management on the ground beetle and spider communities of upland grasslands. J. Appl. Ecol. 26, 489-503.

Sunderland, K.D., De Snoo, G.R., Dinter, A., Hance, T., Helenius, J., Jepson, P., Kromp, B., Samu, F., Sotherton, N.W., Toft, S., Ulber, B., 1995. Density estimation for invertebrate predators in 
agroecosystems, in Toft, S., Riedel, W. (Eds), Arthropod Natural Enemies in Arable Land. I. Density, Spatial Heterogeneity and Dispersal. Acta Jutlandica, Aarhus University Press, Aarhus, Denmark, pp. 133-162.

Symondson, W.O.C., Sunderland, K.D., Greenstone, M.H., 2002. Can generalist predators be effective biocontrol agents? Annu. Rev. Entomol. 47, 561-594.

Topping, C., Sunderland, K.D., 1992. Limitations to the pitfall traps in ecological-sudies exemplified by a study of spiders in a field of winter-wheat. J. Appl. Ecol. 29, 485-491.

Tucker, C.J., 1979. Red and photographic infrared linear combi- nations for monitoring vegetation. Remote Sens. Environ. 8, 127-150.

Uetz, G.W., 1991. Habitat structure and spider foraging. In: Bell, S.S., McCoy, E.D., Mushinsky, H.R. (Eds), Population and community biology Series. Chapman and Hall, London, UK, pp. 325-348.

Uetz, G.W., Url, S., 1979. The influence of variation in litter habitats on spider communities. Oecologia. 40, 29-42.

Varet, M., Burel, F., Lafage, D., Pétillon, J., 2013. Age-dependent colonisation of urban habitats: a diachronic approach using carabid beetles and spiders. Anim. Biol. 63, 257-269.

Vincent, P.J., Haworth, J.M., 1983. Poisson regression models of species abundance. J. Biogeogr. $10,153-160$.

Wamser, S., Diekötter, T., Boldt, L., Wolters, V., Dauber, J., 2012. Trait-specific effects of habitat isolation on carabid species richness and community composition in managed grasslands. Insect Conserv. Diver. 5, 9-18. 
Table 1 : Means \pm s.e. of environmental variables for each plot with GLM results and post-hoc tests.

Temperature is given in ${ }^{\circ} \mathrm{C}$. NDVI $=$ Nomalised difference vegetation index .

\begin{tabular}{cccccccc}
\hline & \multicolumn{4}{c}{ Plots } & \multicolumn{3}{c}{ GLM } \\
& $\mathrm{E}$ & $\mathrm{M}$ & $\mathrm{L}$ & $\mathrm{C}$ & $\mathrm{F}$ & $\mathrm{P}$ & Post-hoc \\
\hline Litter depth & $0.53 \pm 0.17$ & $0.43 \pm 0.25$ & $0.94 \pm 0.37$ & $1.47 \pm 0.63$ & 13.13 & $<0.001$ & $\mathrm{M}=\mathrm{E}=\mathrm{L}<\mathrm{C}$ \\
Average height & $58.75 \pm 11.26$ & $38.5 \pm 24.73$ & $53 \pm 18.74$ & $59 \pm 15.78$ & 2.58 & 0.069 & - \\
Maximum height & $92.5 \pm 12.81$ & $76.5 \pm 27.69$ & $117 \pm 23.59$ & $117 \pm 22.14$ & 7.59 & $<0.001$ & $\mathrm{M}<\mathrm{E}=\mathrm{L}=\mathrm{C}$ \\
& & & & & & & $\mathrm{E}=\mathrm{M}=\mathrm{L}$ \\
Nb plant species & $8.5 \pm 1.77$ & $7 \pm 1.25$ & $8.3 \pm 1.25$ & $5.2 \pm 2.53$ & 7.08 & $<0.001$ & $\mathrm{E}=\mathrm{L}<\mathrm{C}$ \\
Moisture & $27.05 \pm 3.63$ & $23.17 \pm 3.33$ & $24.28 \pm 2.53$ & $23.71 \pm 2.74$ & 2.72 & 0.06 & $\mathrm{E}>\mathrm{M}$ \\
& & & & & & & $\mathrm{E}>\mathrm{M}>\mathrm{L}$ \\
Temperature & $23.82 \pm 0.76$ & $22.68 \pm 0.39$ & $21.76 \pm 0.53$ & $22.34 \pm 0.36$ & 24.71 & $<0.001$ & $\mathrm{E}>\mathrm{C}$ \\
$\quad$ NDVI & $0.18 \pm 0.01$ & $0.20 \pm 0.01$ & $0.18 \pm 0.01$ & $0.22 \pm 0.01$ & 21.31 & $<0.001$ & $\mathrm{E}<\mathrm{M}=\mathrm{L}<\mathrm{C}$ \\
\hline
\end{tabular}


Table 2: ANOVA (and post-hoc test) of management effect on spiders and carabid beetles activitydensity, species richness, functional diversity (FD) and constrained weighted means (CWM) of traits. $\mathrm{C}=$ control plot, $\mathrm{E}=$ early cut plot, $\mathrm{M}=$ medium cut plot, $\mathrm{L}=$ late cut plot.

\begin{tabular}{llll}
\hline SPIDERS & & (M)ANOVA & Post-Hoc \\
\hline Activity density & & $\mathrm{F}=\mathbf{3 . 0 8} ; \mathrm{P}=\mathbf{0 . 0 3 3}$ & $\mathrm{E}=\mathrm{M}=\mathrm{L}=\mathrm{C}$ \\
Species richness & & $\mathrm{F}=0.87 ; \mathrm{P}=0.456$ & \\
FD & All & $\mathrm{F}=2.16 ; \mathrm{P}=0,092$ & \\
& Biotop & $\mathrm{F}=1.49 ; \mathrm{P}=0.221$ & \\
& Guild & $\mathrm{F}=2.26 ; \mathrm{P}=0.085$ & \\
& Lenght & $\mathrm{F}=0.48 ; \mathrm{P}=0.698$ & \\
CWM & Habitat & $\mathrm{F}=1.96 ; \mathrm{P}=0.072$ & \\
& Generalist & - & \\
& Specialist & - & \\
& Guild & $\mathrm{F}=\mathbf{2 . 1 9} ; \mathrm{P}=\mathbf{0 . 0 0 8}$ & \\
& Ambush hunter & $\mathrm{F}=\mathbf{4 . 1 3} ; \mathrm{P}=\mathbf{0 . 0 0 8}$ & $\mathrm{M}>\mathrm{L}=\mathrm{C}$ \\
& Ground runner & $\mathrm{F}=\mathbf{3 . 0 1} ; \mathrm{P}=\mathbf{0 . 0 3 0}$ & $\mathrm{M}<\mathrm{L}$ \\
& Web-builder & $\mathrm{F}=2.32 ; \mathrm{P}=0.079$ & \\
& Lenght & $\mathrm{F}=2.53 ; \mathrm{P}=0.060$ & \\
\hline
\end{tabular}

\begin{tabular}{llll}
\hline CARABIDS & & (M)ANOVA & Post-Hoc \\
\hline Activity density & & $\mathrm{F}=\mathbf{9 . 6 6} ; \mathrm{P}=\mathbf{0 . 0 3 3}$ & $\mathrm{C}>\mathrm{E}=\mathrm{M}=\mathrm{L}$ \\
Species richness & & $\mathrm{F}=\mathbf{9 . 6 9} ; \mathrm{P}<\mathbf{0 . 0 0 1}$ & $\mathrm{C}>\mathrm{E}=\mathrm{M}=\mathrm{L}$ \\
$\mathrm{FD}$ & All & $\mathrm{F}=\mathbf{5 . 8 6} ; \mathrm{P}<\mathbf{0 . 0 0 1}$ & $\mathrm{C}<\mathrm{M}=\mathrm{L}$ \\
& Biotop & $\mathrm{F}=\mathbf{2 . 2 8} ; \mathrm{P}=0.085$ & \\
& Diet & $\mathrm{F}=\mathbf{4 . 1 7} ; \mathrm{P}=\mathbf{0 . 0 0 7}$ & $\mathrm{C}<\mathrm{M}=\mathrm{L}$ \\
& Lenght & $\mathrm{F}=1.27 ; \mathrm{P}=0.290$ & \\
CWM & Biotop & $\mathrm{F}=\mathbf{1 . 9 0 3} ; \mathrm{P}=0.133$ & \\
& Generalist & - & \\
& Specialist & - & \\
& Diet & $\mathrm{F}=\mathbf{3 . 1 5} ; \mathrm{P}=\mathbf{0 . 0 0 1}$ & \\
& Phytophagous & $\mathrm{F}=\mathbf{4 . 4 8} ; \mathrm{P}=\mathbf{0 . 0 0 5}$ & $\mathrm{C}<\mathrm{L}$ \\
& Polyphagous & $\mathrm{F}=\mathbf{4 . 6 6} ; \mathrm{P}<\mathbf{0 . 0 0 1}$ & $\mathrm{C}=\mathrm{E}>\mathrm{M}$ \\
& Predator & $\mathrm{F}=\mathbf{1 . 4 6} ; \mathrm{P}=0.229$ & \\
& Lenght & $\mathrm{F}=\mathbf{4 . 2 9} ; \mathrm{P}=\mathbf{0 . 0 0 3}$ & $\mathrm{C}>\mathrm{M}=\mathrm{L}$ \\
\hline
\end{tabular}


Figure 1: Boxplot of spiders activity-density before (pre) and after (post) cutting for each cutting date. The horizontal bar in the boxplot indicates the median, the ends of the boxes indicate the interquartile range, and the whiskers indicate the 10 and 90th quantiles. $\mathrm{C}=$ control plot, $\mathrm{E}=$ early cut plot, $\mathrm{M}=$ medium cut plot, $\mathrm{L}=$ late cut plot.

Figure 2 : Boxplot of spiders species richness before (pre) and after (post) cutting for each cutting date. See Figure 1 for boxplot and abbreviations meaning.

Figure 3: Boxplot of carabids activity-density before (pre) and after (post) cutting for each cutting date. See Figure 1 for boxplot and abbreviations meaning.

Figure 4: Boxplot of carabids species richness before (pre) and after (post) cutting for each cutting date. See Figure 1 for boxplot and abbreviations meaning. 


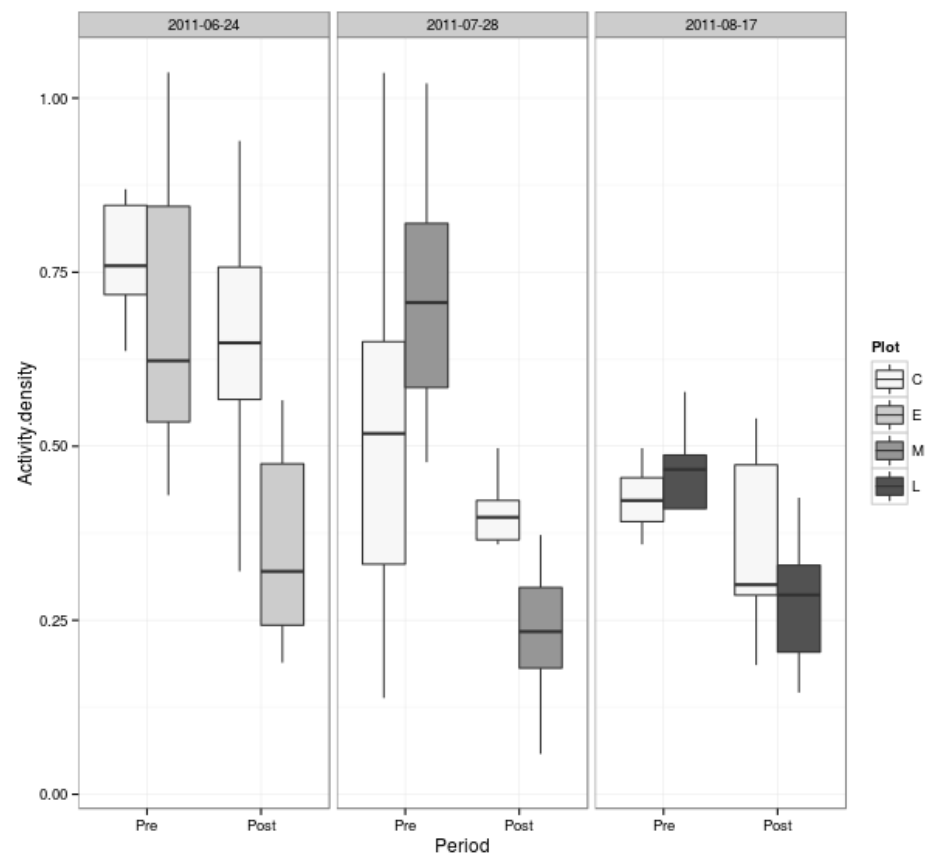

Figure 1: Lafage and Pétillon, 2013 


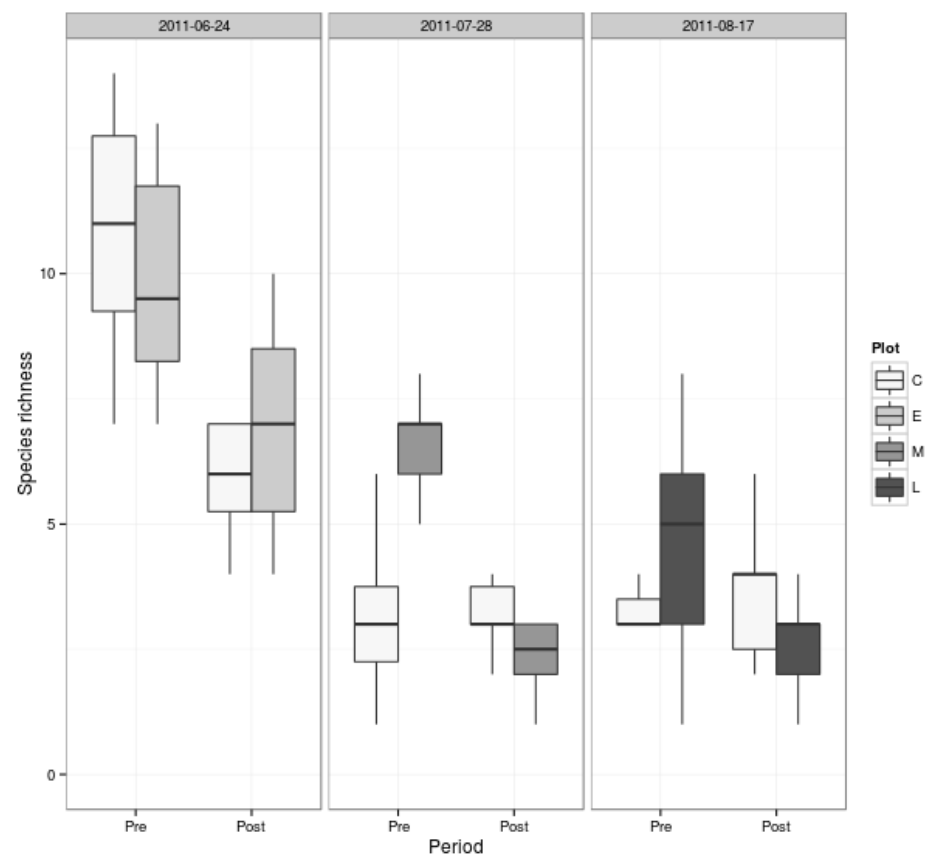

Figure 2: Lafage and Pétillon, 2013 


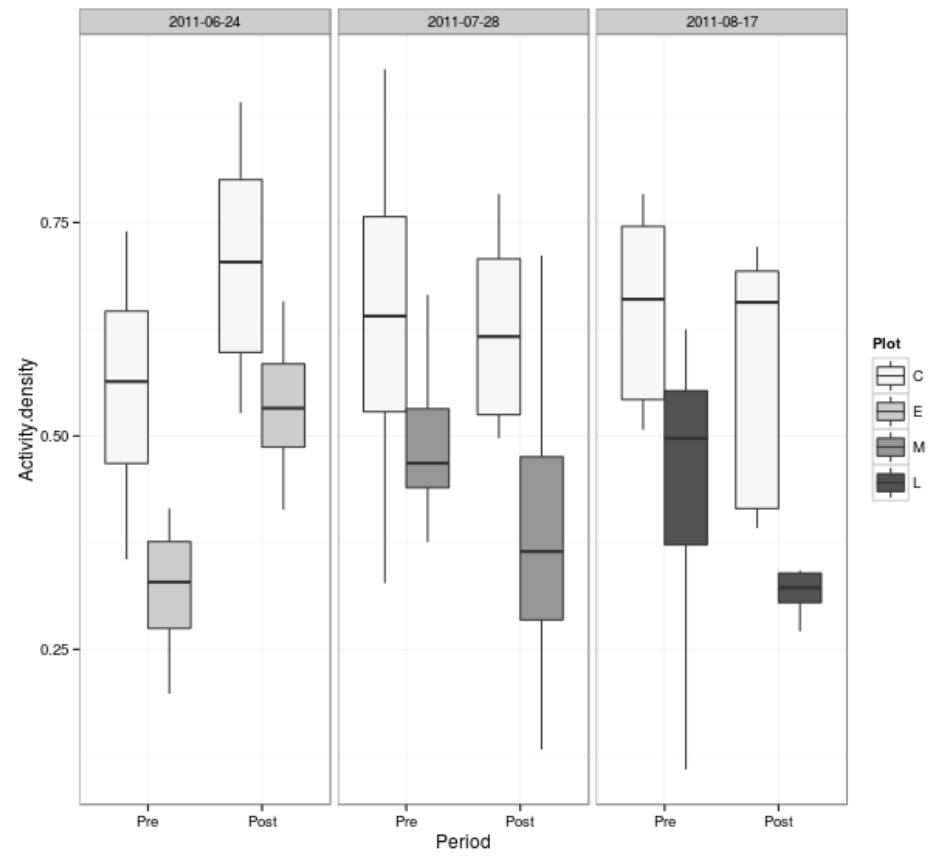

Figure 3: Lafage and Pétillon, 2013 


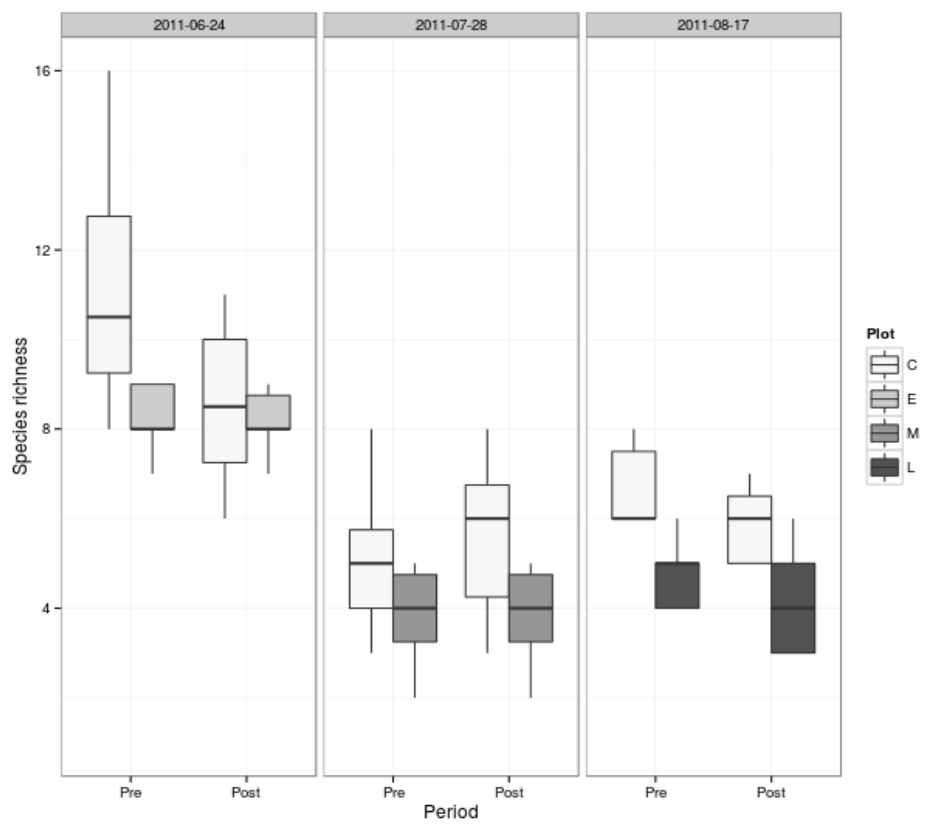

Figure 4: Lafage and Pétillon, 2013 